\title{
DEVELOPMENT OF LARGE CONCRETE OBJECT GEOMETRICAL MODEL BASED ON TERRESTRIAL LASER SCANNING
}

\author{
Janina Zaczek-Peplinska ${ }^{1}$, Paweł Popielski ${ }^{2}$, \\ Adam Kasprzak ${ }^{2}$, Paweł Wójcik ${ }^{1}$
}

1) Faculty of Geodesy and Cartography, Warsaw University of Technology

2) Faculty of Environmental Engineering, Warsaw University of Technology

\begin{abstract}
:
The paper presents control periodic measurements of movements and survey of concrete dam on Dunajec River in Rożnów, Poland. Topographical survey was conducted using laser scanning technique. The goal of survey was data collection and creation of a geometrical model. Acquired cross- and horizontal sections were utilised to create a numerical model of object behaviour at various load depending of changing level of water in reservoir. Modelling was accomplished using finite elements technique. During the project an assessment was conducted to terrestrial laser scanning techniques for such type of research of large hydrotechnical objects such as gravitational water dams. Developed model can be used to define deformations and displacement prognosis.
\end{abstract}

Keywords: terrestrial laser scanning, numerical modelling, finite elements method, technical control of dam, geodetic inventory

\section{Introduction}

In order to define displacements of designed or existing hydrotechnical object it is common to use numerical calculations based on FEM (finite elements method) (Zienkiewicz O.C., 2000). Method used for calculations should model in required scope accurate processes significantly influencing final results and allow for utilization of current knowledge in the field of material parameter change processes. It should also allow for modelling various options of object realisation as well as take into account principal factors influencing analysed process (e.g. generating initial tensions, modelling phased construction erection, ground water level changes all resulting in load changes) (Popielski et al, 2007).

FEM allow for estimating forces and displacements in the subsurface and in constructed or existing object. Depending of object geometry, changes in natural conditions and expected accuracy, numerical simulation can be performed using 2D or 3D models. Analysis of interaction between structure and ground base should be 
established as a monitoring process accompanying the construction phase and further object operation.

This paper presents, using as an example concrete dam in Rożnów, selected contemporary research methods which could be facilitated for developing numerical model of concrete hydrotechnical objects.

With the moment of raising water concrete dams create a potential threat for terrain, people and infrastructure in the river valley downstream. For this reason it is required to perform frequent technical condition assessment and analysis aimed at examination of the structure security. Technical and safety assessments are conducted periodically using results of surveys and data from the monitoring installed within the object.

During the structure safety assessment static analysis should be performed taking into consideration deformation and displacement caused by structure settling and static and dynamic loads acting on structure. Due to large number of issues numerical calculation is a practical tool for conducting such analysis.

Ahead of calculations s suitable model should be prepared including geometry of particular material zones, edge conditions and material parameters and applied in form of changeable in time function physical occurrences. In order to eliminate potential errors every model should be subjected to verification.

\section{Concrete Dam in Rożnów}

Subject of conducted research is a heavy concrete dam located on 80+000 kilometer of Dunajec river in Rożnów village. Dam is a 1st Class hydrotechnical object (Ordinance of Polish Ministry of Environment of 20th April 2007 regarding technical condition requirements to be fulfilled by hydrotechnical buildings and their locations).

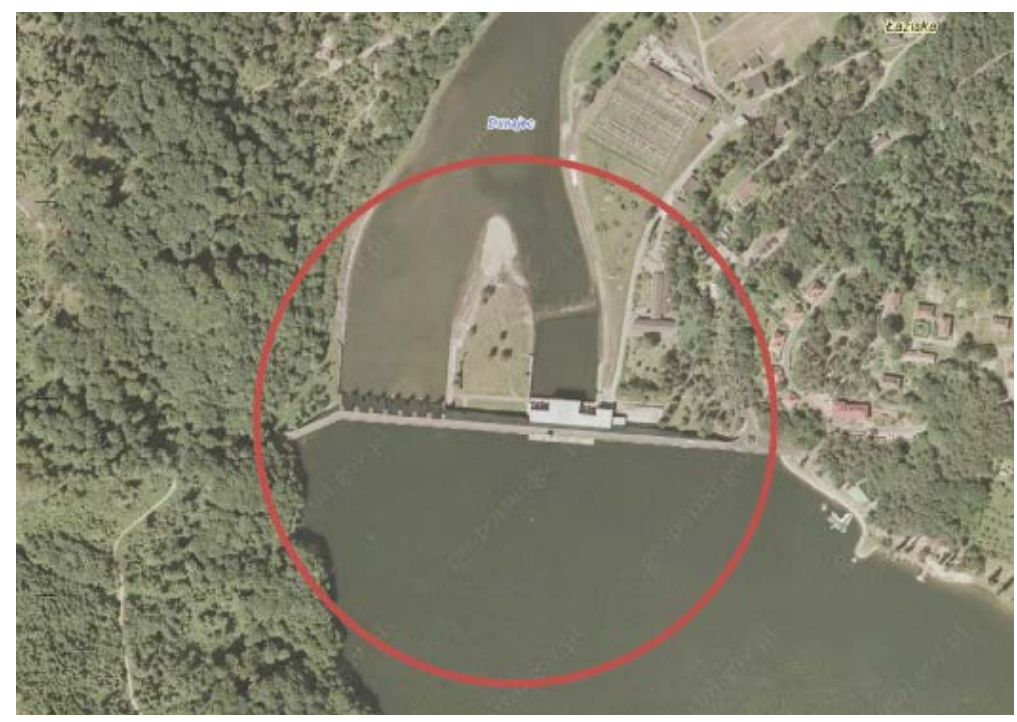

Fig. 1. Rożnów Dam (source: Geoportal)

Rożnów Dam is built of 44 sections:

- 20 non-overflow dam sections each 15 m wide. (Non-overflow sections XVII and XVIII are shown in Fig. 2),

- 12 non overflow sections located within left abutment, $5 \mathrm{~m}$ and 7,5 m wide,

- 7 overflow sections, out of which 5 were fitted with bottom outlets, 
- 5 electric power plant sections, fitted with Kaplan water-turbines (4 sections) and engine room (1 section). (Plant sections $X I X$ and $X X$ are shown in Fig. 2).

Foundation foot for each sections was constructed with 1:10 gradient, declined towards the high water. Sealing of the ground base was executed in form of three rows of cement solution injections (cement slurry).

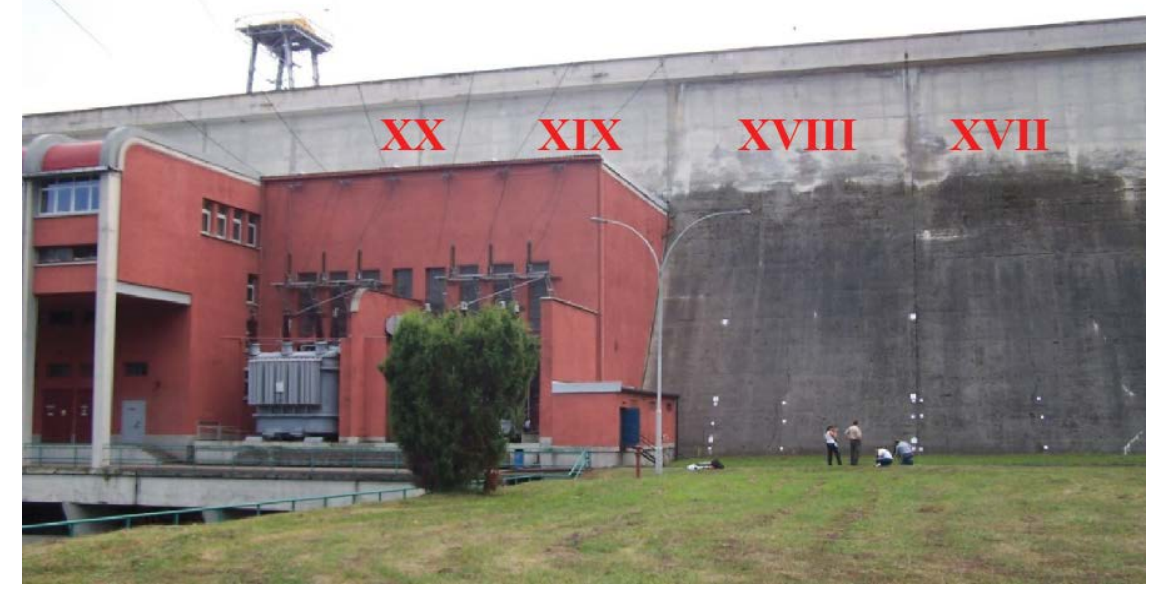

Fig. 2. View of downstream face onto sections XVII - XX (source: author's archive)

Rożnów Dam was constructed on the ground characteristic for the areas to the north of Karpaty mountains. Dunajec valley within the dam location is made up of layers of sandstone, loam slate and alternating conglomerates (Balcerski, 1938). Rock formations are covered with alluvial deposit layer 5-10 m thick. Upper rock layer is weathered. Dam foundations could be therefore situated around level ordinate 230 MSL.

Rock bed layers are inclined at $20-25^{\circ}$ in relation to the dam axis, whereas dip towards the upstream of the river equals $26-32^{\circ}$. There are 4 displacement faults in the ground, which disturb continuity of rock layers (Fig. 3. and 4.).

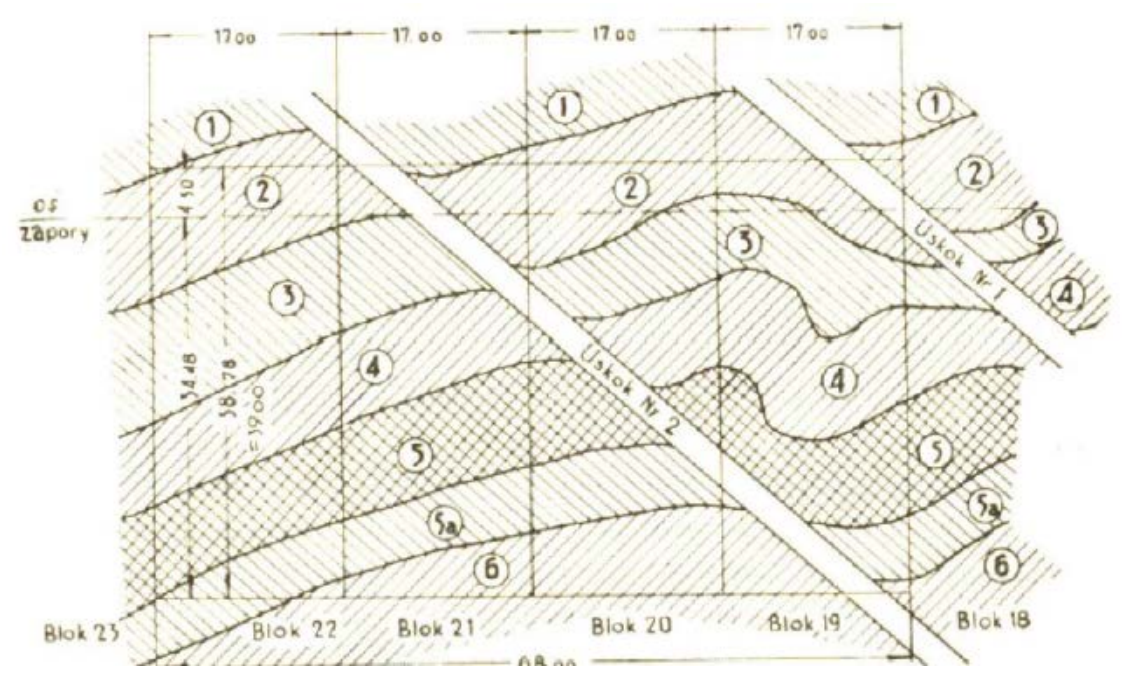

Fig. 3. Rock layers arrangement (Balcerski, 1938) 


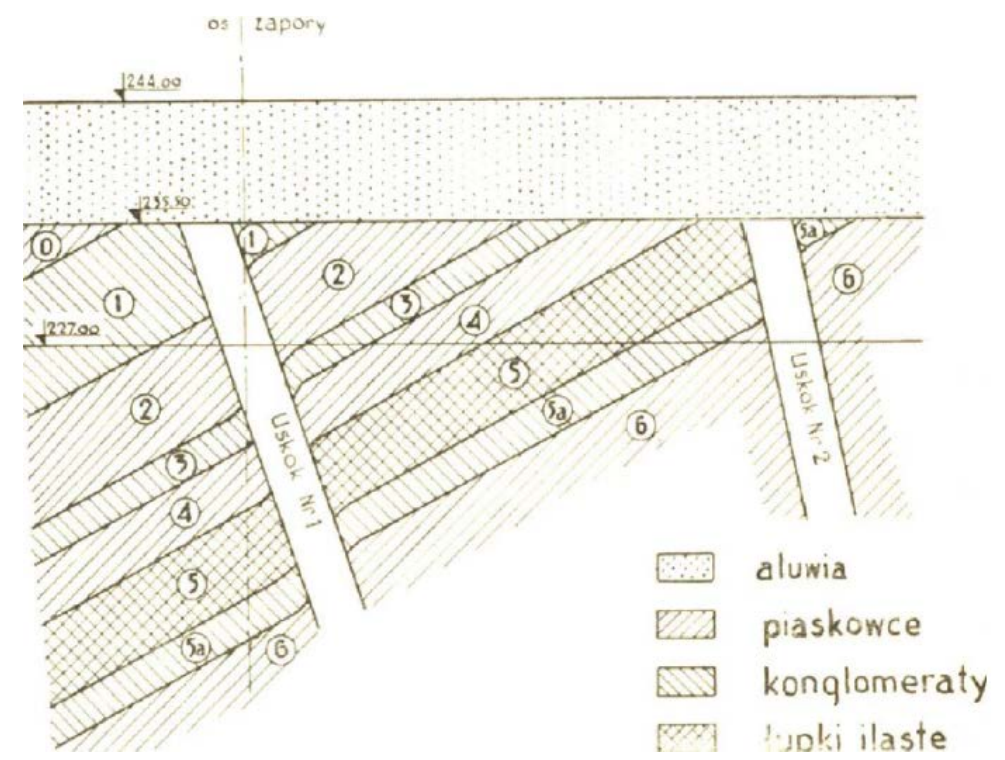

Fig. 4. Geological cross-section on the edge of section XVIII and XIX (Balcerski, 1938)

Such conditions ensure high durability of base thank to sandstones and tightness through occurrence of loamy slates. Also loam slate negatively affect the static of the construction, due to its occurrence as inserts in a sandstone layers, and lowering the friction factor when damp. Concrete sealing was made in form of cement slurry injections though 40-120mm diameter drilled holes. Water and cement proportions are determined based on sealed medium porosity and vary between 1 to 1 and 1 to 10. In Rożnów two rows of injections (creating an upper and lower screen) were made to a depth of 30-35 metres below the foundation level. Lower screen was created yet before pouring concrete foundations. This procedure helped to strengthen rock bed layers. Holes which were used to pump cement slurry were drilled every 6 metres at the $60^{\circ}$ from level. This assured cutting through the highest number of cracks in the rock bed. Upper screen was created after pouring lower part of foundations to the height of 10 metres 5 metres away from the dam axis towards the upper water/reservoir. The last screen, so called "gallery", aimed at sealing subsurface was injected from the lower inspection-injection gallery.

\section{Laser scanning survey method}

Difficult terrain conditions accompanying dam sites determine selection of specialist instruments as well as appropriate geodesic measuring techniques. Advantage of contemporary technique, such as terrestrial laser scanning is an opportunity to execute many observation in a short timescale and simple handling which allow for reduced surveying crew. Proximity of water environment affect local microclimate conditions, which not always conduce to observations of expected accuracy.

Scanners can be divided in two groups, phase based scanners and pulse based scanners. The range of observations is determined by the scanning technology. Phase based scanners are dedicated for closer distances (currently up to $200 \mathrm{~m}$ ), whereas pulse based scanners allow for measuring objects situated much further away from the observation point (up to few kilometres). Depending on the measuring distances scanners are categorised into: short, medium and long range. This entail second characteristic: measurement accuracy. Accuracy values depend of the distance measuring mode (phase based or pulse based) and instrument type and 
model and vary between couple of millimetres and several centimetres (Kaspar et al., 2004).

Definition of laser scanning accuracy is difficult since it is influenced by factors such as:

- distance between the scanned object and the instrument,

- weather conditions,

- accuracy of determination of tie-in points for different scans,

- accuracy of reference to the external coordinate system,

- laser beam incidence angle,

- type and colour of reflecting surface,

- wavelength,

- object geometry, which can cause an "multi-way" effect,

- surrounding light,

- instrument errors.

Final results of laser scanning are not single points coordinates, but geometrical model inscribed into obtained points cloud. During the survey at the Rożnów dam, conducted by Geodesy and Cartography Students Society "Geoida", pulse based scanner Riegl VZ-400 has been used.

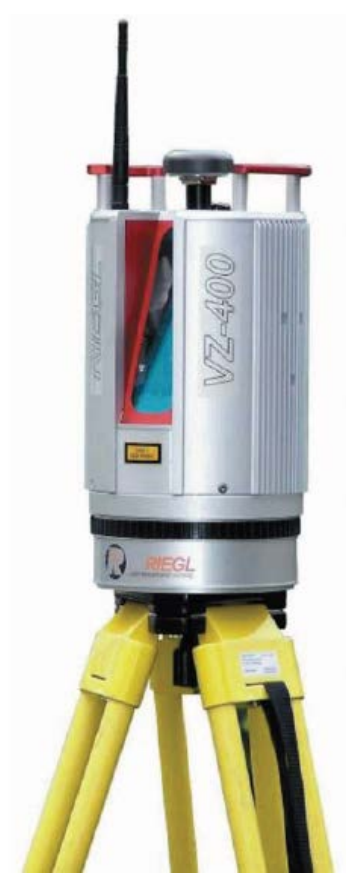

Fig. 5. Pulse based laser scanner (source: Riegl) 


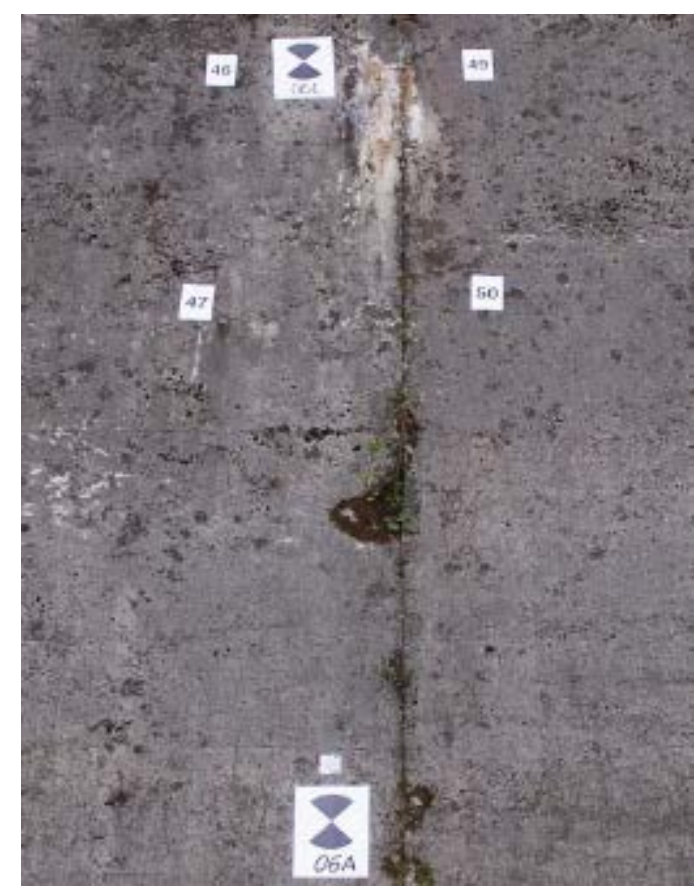

Fig. 6. Used survey targets on the concrete surface.

Cloud points were combined in ASCAN software based on characteristic points on the dam, or special survey markers (Fig. 6.)

During the results data handling first the measured control points on two first scans were adjusted and aligned, and then rest of point clouds were adjusted accordingly. It helps to define how precise can we determinate points on scans. In total 108 tie points were measured with an average deviation for aligned point clouds equal to $m x=0,05031 \mathrm{~m}, \mathrm{my}=0,048443 \mathrm{~m}$. Average error for all scans alignment equaled $0,06984 \mathrm{~m}$.

Fig. 7. present research results. Using ORTHO software provided with ASCAN application an orthophotograph of the dam downstream face was created. In the same software cross-sections of the dam were created Fig. 8. Elaboration of the laser scanning results were performed by members of the Geodesy and Cartography Students Society "Geoida". 


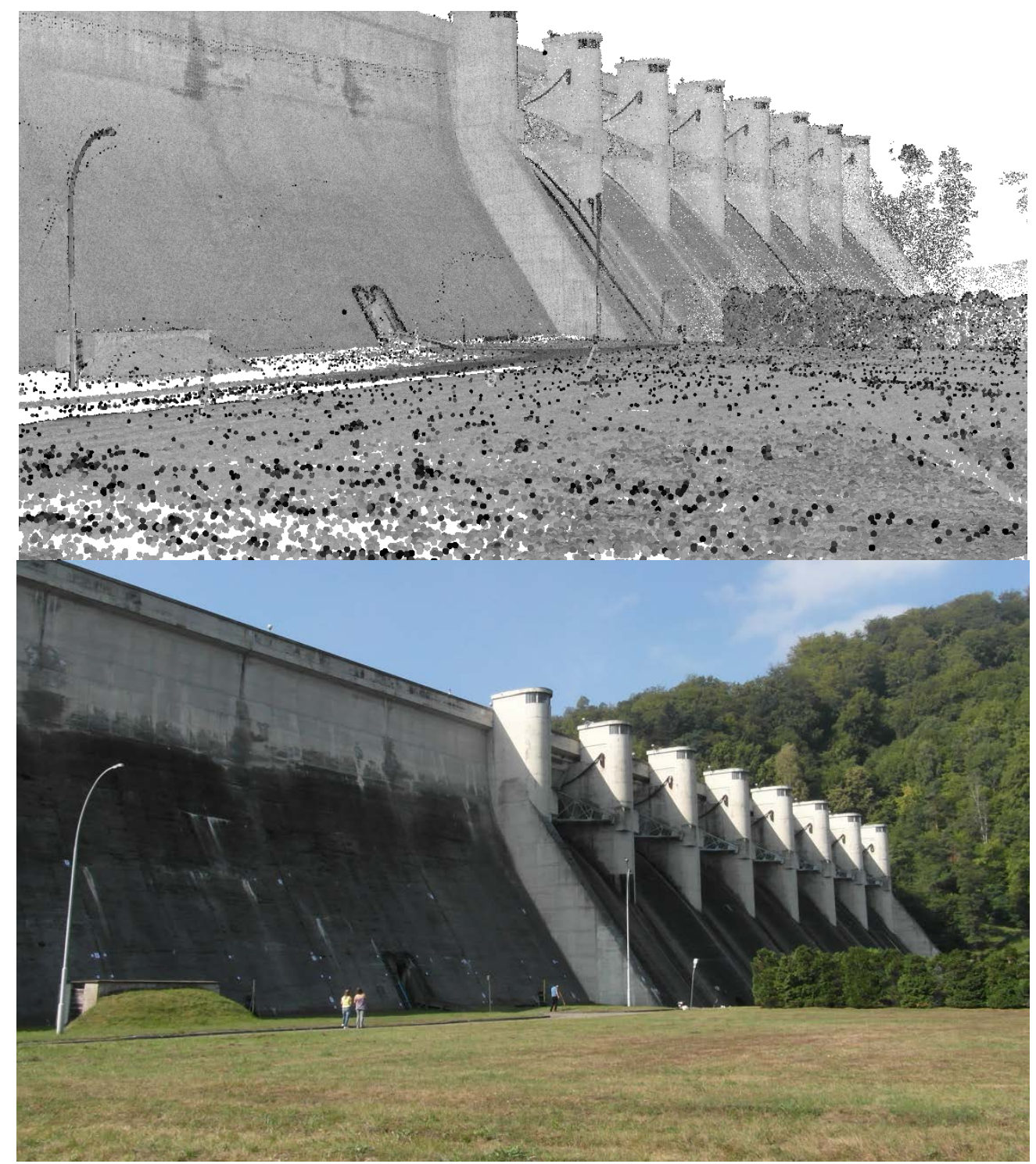

Fig. 7. Comparison of point cloud visualization with a digital picture (source: authors archive)

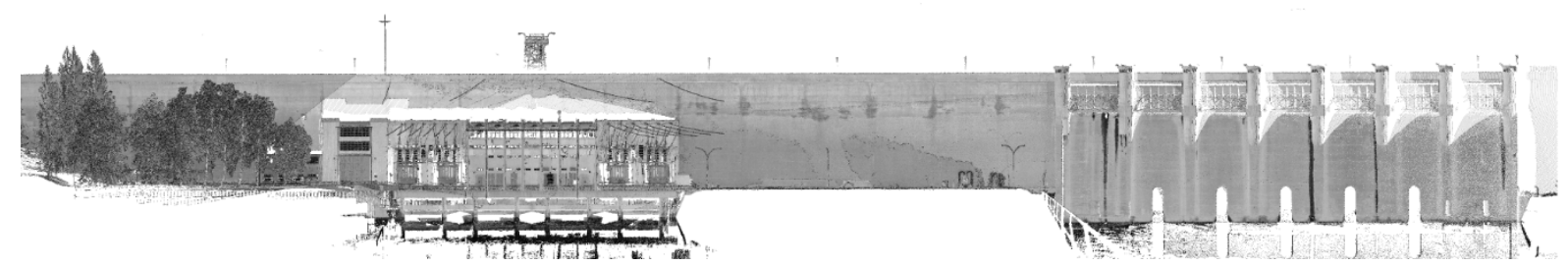

Fig. 8. Orthophotograph of the dam downstream face created using ORTHO software. 


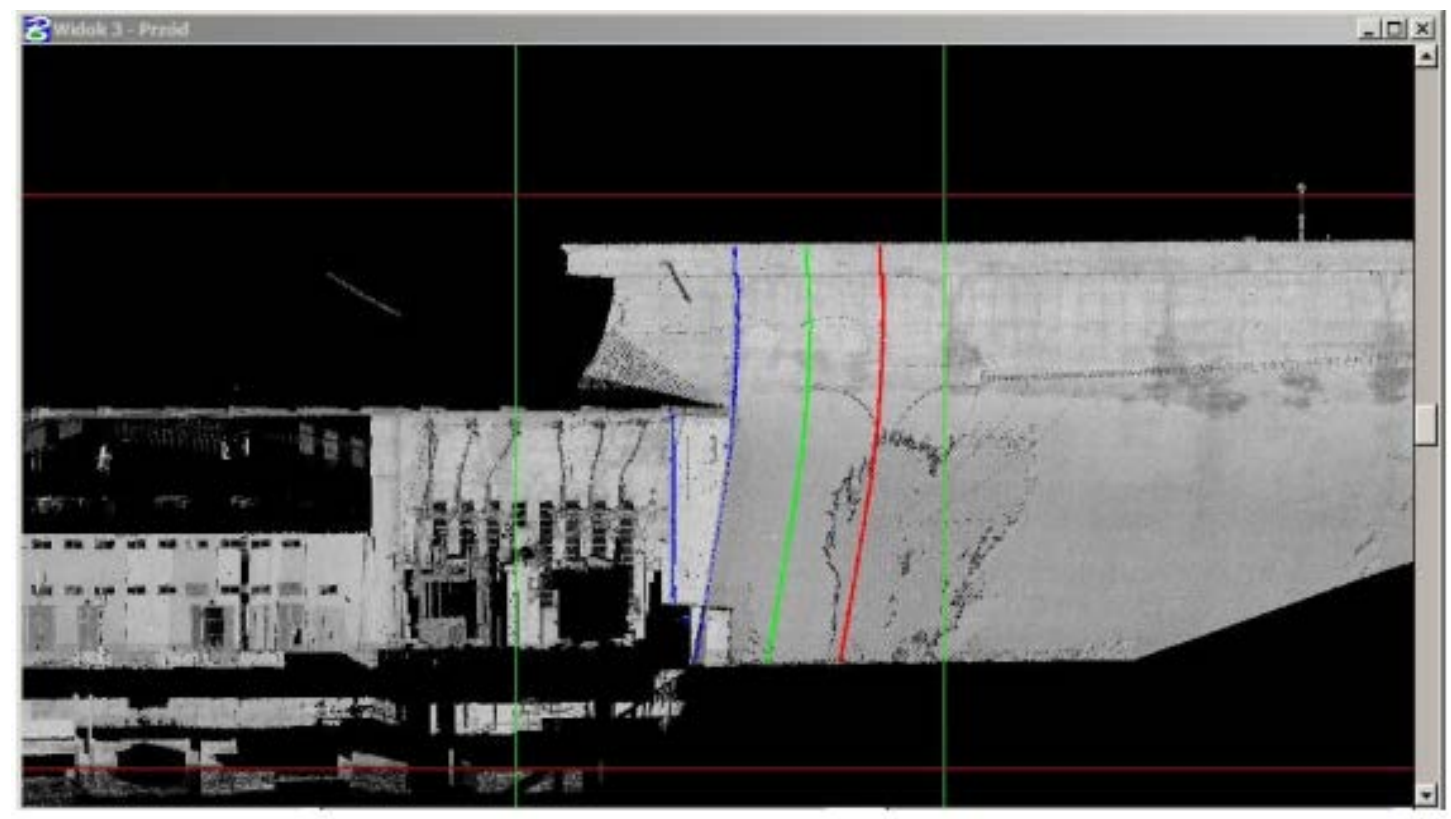

Fig. 9. Generating cross sections in the point cloud.

\section{Numerical model preparation}

Numerical models should be prepared for the whole dam accordingly to the computer capabilities and analysis requirements. Based on preliminary calculation results it can be established which sections will be liable and prone to adverse conditions, and conduct detailed calculations for selected sections.

Section XVIII od dam was subject of modeling. It is deepest founded typical section. It is neighboring power plant blocks. Engineering software such as Z-Soil was used to conduct model calculations. Software utilizes the finite elements method and is designated for solving geotechnical and hydrological problems. Researched section geometry was established based on archival German and Polish plans. Stratigraphic arrangement of geological layers was adopted based on articles and surveys published in 30's last century (Balcerski, 1938). Sealing screens made as injected cement slurry were modeled as rock layers characterized with lower filtration factor and higher strength. Material parameters were based on data obtained from dam archives and from literature.

Dam geometry was created in AutoCAD software as 2D section. Subsequently two dimensional model was imported to Z-Soil software, where 3D it was developed into 3D model. Table 1 presents specification of material zones implemented in model. Materials number $8,10,9,11$ have higher strengths characteristics. It reflects arrangement of anti-filtration screen zones.

After applying appropriate material parameters boundary values in form of high and low water level were applied on the edges of the model, as well as edge conditions relating to the displacements. On lower model plane unmovable supports were located within each node of the mesh, whereas towards the sides supports allowing for vertical movements were placed. Boundary-value analysis are presented in Fig. 10. Fig. 11 represents dam model. 
Table 1. Presentation of material zones

\begin{tabular}{|c|c|c|}
\hline & 1 & Concrete \\
\hline 2 & 8 & Alluvium \\
\hline & 3 & Anti-filtration screen \\
\hline 5 & 10 & Conglomerates \\
\hline 4 & 9 & Loam slate \\
\hline 6 & 11 & Sandstone \\
\hline 7 & 12 & $\begin{array}{c}\text { Seepage - special element allowing for } \\
\text { outflow of water from the model applied } \\
\text { on the edge of the area }\end{array}$ \\
\hline
\end{tabular}

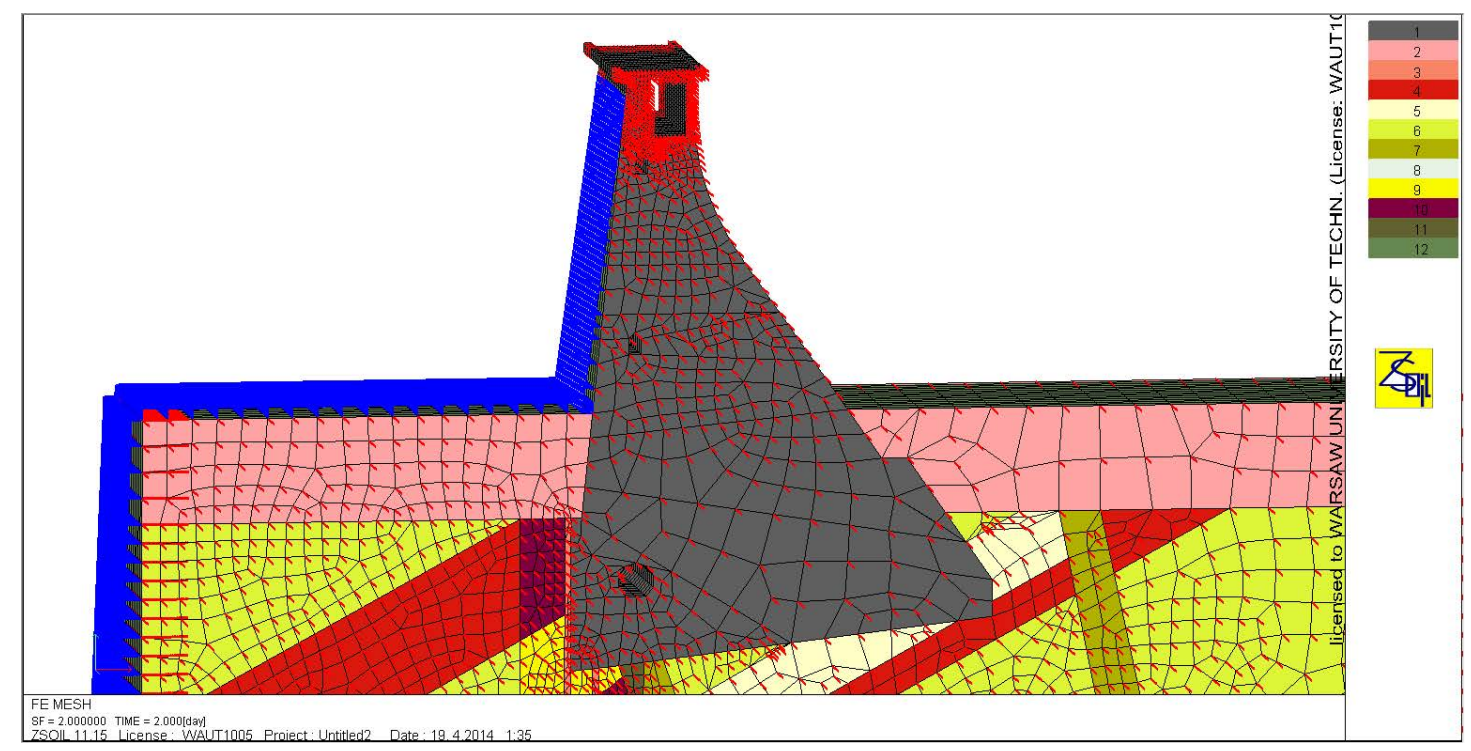

Fig. 10. Dam model with boundary values.

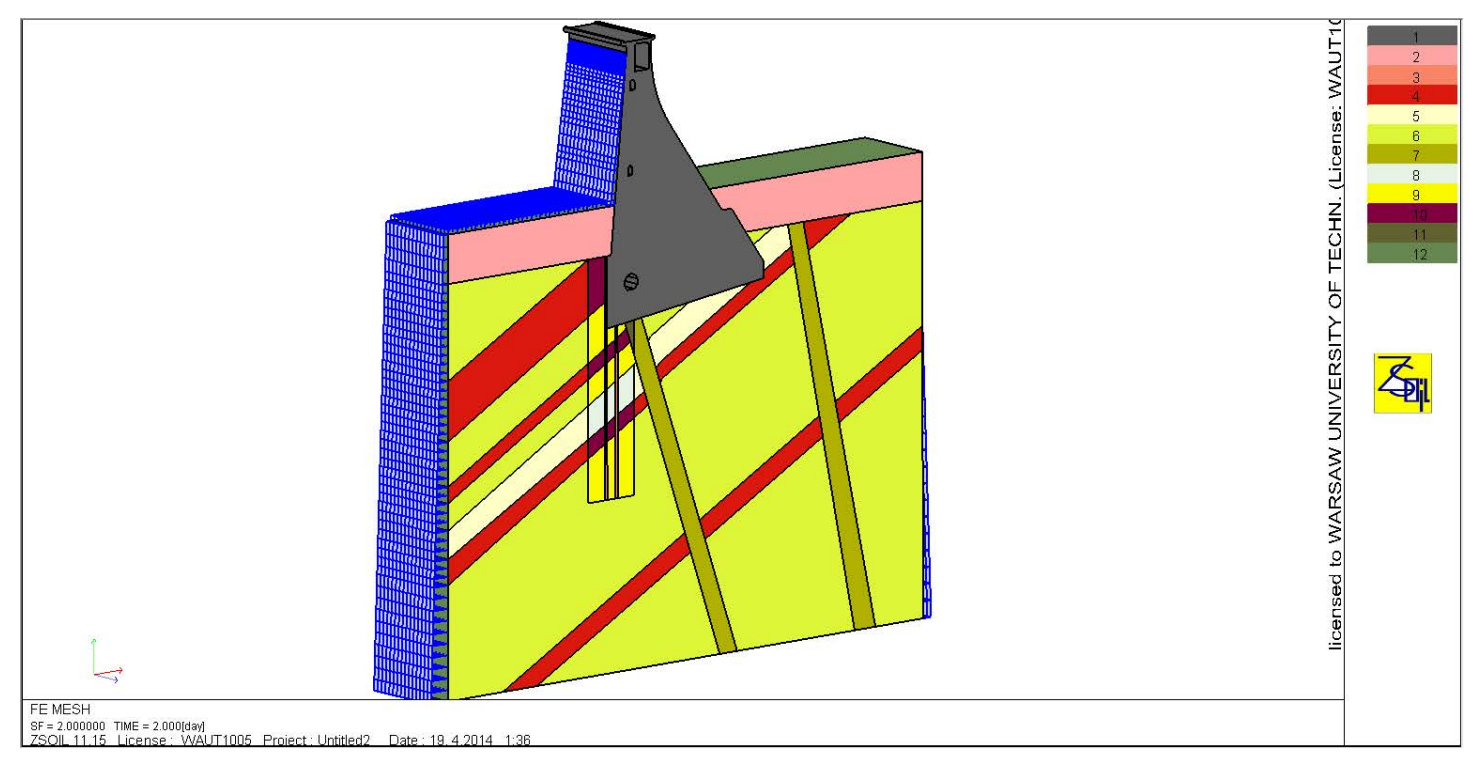

Fig. 11. Dam model. 


\section{Model geometry verification}

In order to validate the numerical model it is necessary to verify obtained outcomes with results of survey and control results. Geometry od researched model was compared to the model created using laser scanning. For this purpose generated from point clouds vertical cross-sections were overlaid onto cross section used to create the model. (Fig. 12.) Comparison was performed in AutoCAD software.

Each of used colours represent one of acquired sections. Ground level was used as a common reference point for all sections. Due to restrictions of laser scanning methods verification does not include both sides of the dam. Only the downstream face of the dam was surveyed. Upstream dam face was not elaborated due to lack of access and no possibility to perform measurements during the high water in the reservoir. As Fig. 12. show it is clear that closer to the top of the dam it gets, the differences between the sections are getting bigger. They are legible in point $D$, where the discrepancies are about $2,5 \mathrm{~cm}$. Highest discrepancies $(6,2 \mathrm{~cm})$ were obtained for point $A$ located on the top of the dam. Variations might be result of measurement inaccuracy or a localised concrete cavities. In case of concrete water dam obtained results are insignificant and will have no influence on correctness of numerical results.

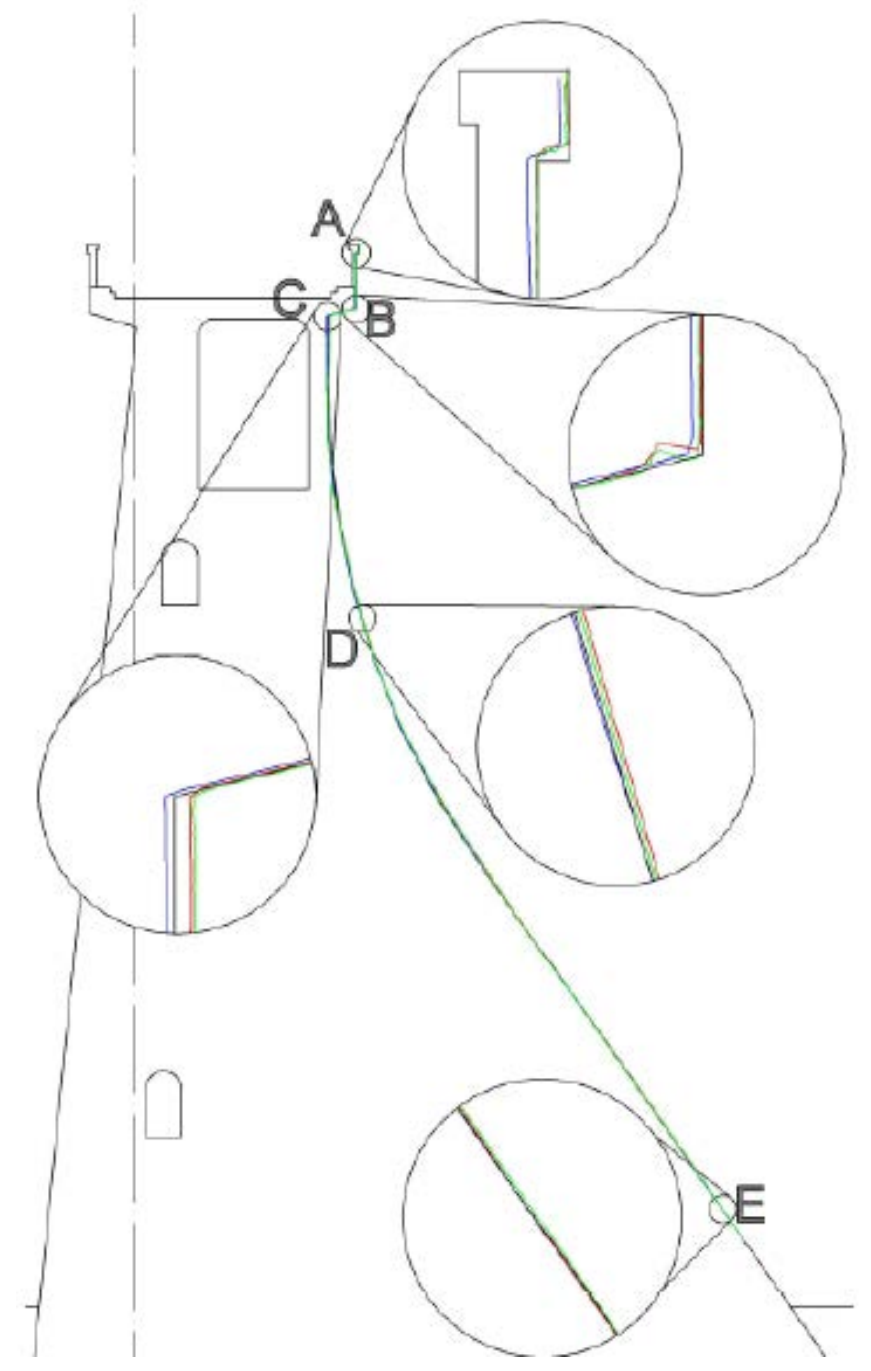

Fig. 12. Section XVIII geometry and point cloud comparison. 


\section{Conclusions}

Laser scanning method offers sufficient survey measuring accuracy for a large concrete objects such as water dams. Based on conducted analysis a choice of methods which can be used for obtaining data to create a numerical model were selected.

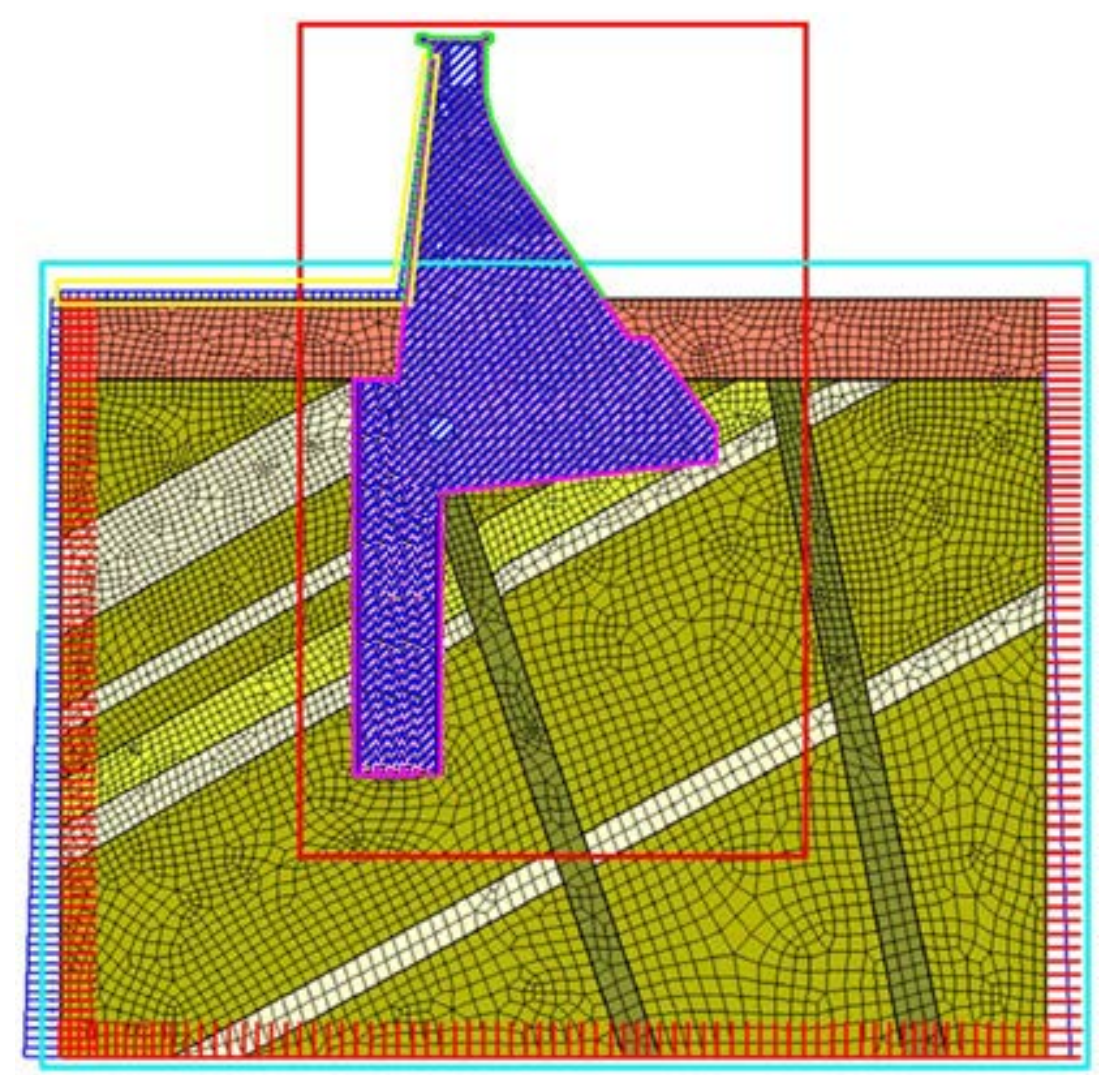

Fig. 13. Isometrical map in form of sections every $7.5 \mathrm{~m}$.

Fig. 13. present recomended sources of data, where:

- red rectangle highlights areas where data can be obtained from object documentation, such as construction specification,

- light blue rectangle mark data which can be obtained by processing precise level survey results, which allow predicting vertical movement caused by ground changes caused for instance by changing seasons,

- yellow colour show boundary values, such as high and low water levels, which can be obtained from the Building Log,

- blue hatch area represents material data which can be acquired through various material examinations,

- dashed green line mark the geometry of the upstream face, which cannot be scanned or measured, due to lack of access, and also lack of place to set up a survey base, also the scanning is restricted by water surface.

In relation to the laser scanning, according to the research performed in years 20122013, it can be stated that:

- type and accuracy of the final outcome of laser scanning data elaboration is adequate to verification and support of creating numerical models of built objects behavior, 
- terrestrial laser scanning survey is economically justified and require less engagement from person involved in measurements compared to traditional techniques, which reduce risk of error,

- laser scanning can be successfully utilized for verification of behavior models especially for supple objects, of complicated shapes, or for other reasons difficult to measure using traditional methods,

- data obtained using laser scanning methods truly reflect the accurate geometry of surveyed object. Obtained point cloud provide a source for further analysis, building 2D and 3D models, creating animations and visualizations.

\section{References}

Balcerski W. (1938): Problemy statyczne fundowania zakładu wodno-elektrycznego w Rożnowie / Static problems of founding the hydro-electric plant in Rożnów. Bimonthly journal "Gospodarka Wodna", Warszawa 1938;

Kaspar M., Pospisil J., Stroner M., Kremen T., Tejkal M. (2004): Laser scanning in civil engineering and land surveying. Hradec Kralove, Republika Czeska,: Vega s.r.o., 2004;

Popielski P, Zaczek-Peplinska J. (2007): Wykorzystanie modeli numerycznych w eksploatacji budowli pietrzących / Utilisation of numerical models in exploitation of damming structures, Materiały XII Międzynarodowej Konferencji Technicznej Kontroli Zapór / XII International Conference Technical Control od Dams, ss. 241255, Stare Jabłonki, Poland, 2007, ISBN 976-83-88897-88-7

Popielski P., Zaczek-Peplinska J. (2013): Utilisation of terrestrial laser scanning for verification of geometry of numerical models of hydrotechnical structures using the example of a section of the concrete Besko dam. Accepted article for Technical Transactions, series Environmental Engineering, Cracow University of Technology Press, 2013.

Zienkiewicz O.C, Taylor R.L. (2000): The Finite Element Method. Fifth edition, Butterworth-Heinemann, 2000;

Rozporządzenie Ministra Środowiska z dnia 20 kwietnia 2007 r. w sprawie warunków technicznych, jakim powinny odpowiadać budowle hydrotechniczne i ich usytuowanie / Ordinance of Polish Ministry of Environment of $20^{\text {th }}$ April 2007 regarding technical condition requirements to be fulfilled by hydrotechnical buildings and their locations, Dz.U. 2007 nr 86 p. 579;

\section{Authors:}

Janina Zaczek-Peplinska ${ }^{1)}$, jzaczek@gik.pw.edu.pl

Paweł Popielski ${ }^{2)}$, pawel.popielski@is.pw.edu.pl

Adam Kasprzak ${ }^{2)}$, adam.kasprzak@is.pw.edu.pl

Paweł Wójcik ${ }^{1)}$, p.wojcik@geoida.pw.edu.pl

1) Warsaw University of Technology, Faculty of Geodesy and Cartography

pl. Politechniki 1, 00-661 Warsaw, Poland

2) Warsaw University of Technology, Faculty of Environmental Engineering

Hydro-Engineering and Hydraulics Department

20 Nowowiejska str., 00-653 Warsaw, Poland 